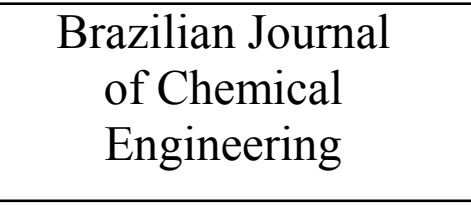

ISSN 0104-6632

Printed in Brazil www.abeq.org.br/bjche

Vol. 23, No. 04, pp. 555 - 561, October - December, 2006

\title{
ADSORPTION OF LIGHT ALKANES ON COCONUT NANOPOROUS ACTIVATED CARBON
}

\author{
K. S. Walton ${ }^{1}$, C. L. Cavalcante Jr. ${ }^{1,2 *}$ and M. Douglas LeVan ${ }^{1}$ \\ ${ }^{1}$ Vanderbilt University, Chemical Engineering Department, \\ VU Station B 351604, 2301 Vanderbilt Place \\ 37235-1604 Nashville - TN, USA. \\ ${ }^{2}$ Universidade Federal do Ceará, Departamento de Engenharia Química, \\ Campus Pici, Bl. 709, 60455-760, Fortaleza - CE, Brazil. \\ E-mail: celio@gpsa.ufc.br
}

(Received: October 7, 2005 ; Accepted: September 10, 2006)

\begin{abstract}
This paper presents experimental results for adsorption equilibrium of methane, ethane, and butane on nanoporous activated carbon obtained from coconut shells. The adsorption data were obtained gravimetrically at temperatures between 260 and $300 \mathrm{~K}$ and pressures up to 1 bar. The Toth isotherm was used to correlate the data, showing good agreement with measured values. Low-coverage equilibrium constants were estimated using virial plots. Heats of adsorption at different loadings were also estimated from the equilibrium data. Adsorption properties for this material are compared to the same properties for BPL activated carbon and BAX activated carbon.
\end{abstract}

Keywords: Activated carbon; Aalkane adsorption; Gas storage.

\section{INTRODUCTION}

Light alkanes adsorption on activated carbons has been studied by several authors (Do and Do, 1994; Russell and LeVan, 1997; Mangun et al., 1997; Holland et al., 2001; Al-Muhtaseb et al., 2001), normally using available standard commercial carbons. The appropriate description and analysis of light alkanes adsorption on carbon adsorbents is critical in the design of important current practical applications, such as volatile compounds removal, gas effluent treatments, natural gas storage, etc. Specifically for natural gas storage and delivery, the effect of $\mathrm{C} 2^{+} \mathrm{s}$ alkanes composition and their adsorption behavior in a cyclic charge/discharge process can be of utmost importance in the appropriate definition of economic and technical viability of a given project (Mota, 1999).
Studies on activated carbons as possible natural gas storage medium have been widely reported for various types of carbon materials (Matranga et al., 1992; Chang and Talu, 1996; Mota et al., 1997; Inomata et al., 2002; Lozano-Castello et al., 2002; Biloe et al., 2002; Tanaka et al., 2002; Molina-Sabio et al., 2003; Perrin et al., 2004), usually focusing on methane as the main constituent of natural gas. In a recent study (Cavalcante et al., 2003) activated carbon obtained from coconut shell was evaluated in regards to methane adsorption at pressures up to 40 bar.

In this paper we present the pure-component equilibrium data for adsorption of methane, ethane, and butane on the nanoporous activated carbon material prepared using coconut shell as a precursor. This data, and their proper representation and understanding, will be necessary in the future

*To whom correspondence should be addressed 
modeling and simulation of charge/discharge cycles in a practical system for storage and delivery of adsorbed natural gas. The data are evaluated using the Toth isotherm. Heats of adsorption, which can play a significant role in the practical design of the system (Chang and Talu, 1996; Mota et al., 1997), are estimated from the isotherms experimental data and evaluated with regards to adsorbent alkane loading.

\section{EXPERIMENTAL}

\section{Materials}

The nanoporous activated carbon sample, obtained from coconut shells by chemical and physical activation, with a BET surface area of ca. $2100 \mathrm{~cm}^{2} / \mathrm{g}$, was kindly supplied by Professor Emerson Jaguaribe (UFPB, Joao Pessoa, Brazil). Details about the preparation of this sample can be found elsewhere (Cavalcante et al., 2003). Methane, ethane, and butane gases were $99 \%$ pure.

\section{Adsorption Measurements}

Adsorption isotherms were measured for methane, ethane, and butane using a standard gravimetric set-up consisting of a Cahn D-200 microbalance. Prior to each experimental run, the sample was regenerated in situ at temperatures up to $100^{\circ} \mathrm{C}$ under vacuum. The temperature of the sample was controlled during adsorption measurements by a
50/50 ethylene glycol/water bath with constant recirculation.

\section{RESULTS AND DISCUSSION}

\section{Adsorption Isotherms}

Isotherms were measured for methane, ethane, and butane at temperatures between 260 and $300 \mathrm{~K}$. Desorption data were also measured for the components to test the reversibility of the adsorption isotherms. The experimental data were described using the Toth equation, given by

$$
\mathrm{n}=\frac{\mathrm{n}^{\mathrm{s}} \mathrm{p}}{\left(1 / \mathrm{K}+\mathrm{p}^{\mathrm{m}}\right)^{1 / \mathrm{m}}}
$$

and a temperature-dependent Toth equation given by (Taqvi et al., 1999):

$$
\begin{aligned}
& \mathrm{p}=\left[\frac{\mathrm{b}}{\left(\mathrm{n} / \mathrm{n}^{\mathrm{s}}\right)-1}\right]^{1 / \mathrm{t}} \\
& \mathrm{b}=\mathrm{b}_{0} \exp \left(-\frac{\mathrm{t} \Delta \mathrm{H}}{\mathrm{RT}}\right)
\end{aligned}
$$

Parameters for the Toth and multi-temperature Toth fits are shown in Tables 1 and 2, respectively.

Table 1: Parameters for Toth Equation (Eq. 1).

\begin{tabular}{|c|c|r|r|r|}
\hline Component & $\mathbf{T}(\mathbf{K})$ & $\mathbf{n}^{\mathbf{s}}$ & $\mathbf{M}$ & $\mathbf{K}$ \\
\hline \multirow{3}{*}{ Methane } & 298 & 3.109 & 1.382 & $3.810 \cdot 10^{-4}$ \\
& 290 & 4.826 & 1.077 & $1.533 \cdot 10^{-3}$ \\
& 280 & 30.71 & 0.5736 & $1.310 \cdot 10^{-2}$ \\
& 265 & 21.21 & 0.5392 & $2.851 \cdot 10^{-2}$ \\
\hline \multirow{3}{*}{ Ethane } & 298 & $2.130 \cdot 10^{3}$ & 0.1417 & 0.3730 \\
& 290 & 106.3 & 0.2496 & 0.2774 \\
\hline \multirow{3}{*}{ n-Butane } & 280 & 26.44 & 0.3980 & 0.1931 \\
& 298 & 27.54 & 0.2113 & 1.533 \\
& 290 & 0.1429 & -0.0823 & 3.350 \\
& 280 & 88.34 & 0.1265 & 1.972 \\
\hline
\end{tabular}

Table 2: Parameters for Multi-temperature Toth Equation (Eqs. 2 and 3).

\begin{tabular}{|c|c|c|c|}
\hline Parameter & & Ethane & n-Butane \\
\hline $\mathbf{t}$ & 0.6546 & 0.2616 & 0.2093 \\
$\mathbf{n}^{\mathbf{s}}$ & 14.67 & 83.21 & 30.43 \\
$\mathbf{b}_{\mathbf{0}}$ & 8556 & 43.12 & 12.12 \\
$\Delta \mathbf{H}$ & 16.47 & 22.81 & 33.89 \\
\hline
\end{tabular}


Figures 1 and 2 show the experimental data described by Eqs. (1) and (2), respectively. Both equations provide a good description of the data, but Eq. (2) requires only one set of parameters for each component. Eq. (1) must be fit for each component at each temperature. The data show the expected behavior of increasing adsorption with increasing carbon number. From desorption measurements, all three components were found to have reversible isotherms. Methane adsorption is comparable to that on other activated carbon samples. However, this material is found to have a high capacity for butane, even at room temperature, with loadings as high as 9 $\mathrm{mol} / \mathrm{kg}$. These loadings are higher than what was reported for butane adsorption on some commercial activated carbons, such as BPL (Pigorini, 2000) and Westvaco BAX-1100 (Holland et al., 2001), as reported in Table 3.

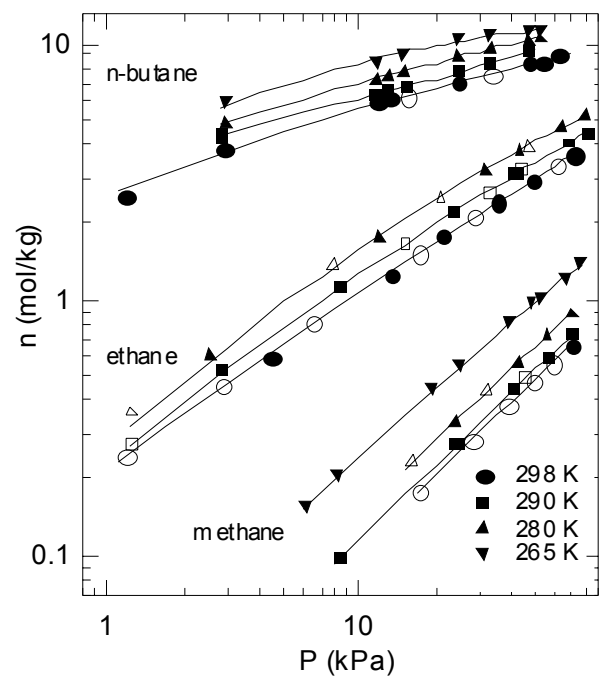

Figure 1: Pure-component adsorption isotherms on coconut activated carbon. Symbols are experimental data. Open symbols indicate desorption measurements. Solid lines are Toth equation Eq. (1).

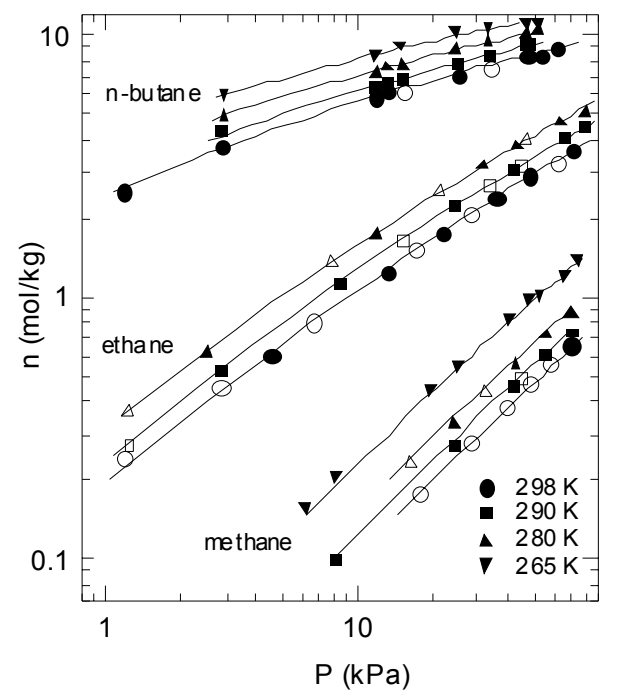

Figure 2: Pure-component adsorption isotherms on coconut activated carbon. Symbols are experimental data. Open symbols indicate desorption measurements.

Solid lines are temperature-dependent Toth equation Eq. (2). 
Table 3: Comparison of Coconut Activated Carbon with BPL and BAX Activated Carbons.

\begin{tabular}{|l|r|r|r|r|}
\hline Property & & Methane & Ethane & n-Butane \\
\hline Loading, mol/kg & I* & 0.7 & 3.6 & 9.1 \\
@ 298K, 70kPa & II & 0.8 & 3.0 & 4.2 \\
& III & 0.5 & 2.3 & 6.1 \\
\hline Henry's Law Constants & I* & 0.00955 & 0.174 & 6.69 \\
$\mathrm{kPa}^{-1} @ 298 \mathrm{~K}$ & II & 0.0203 & 0.72 & 1521.7 \\
& III & 0.00976 & 0.72 & 50.86 \\
\hline $\mathrm{H} \mathrm{@} \mathrm{Low} \mathrm{Coverage}$ & I* & 18.6 & 33.6 & 30.2 \\
$\mathrm{~kJ} /$ mol & II & 21.0 & 34.5 & 59.8 \\
& III & 24.5 & 40.9 \\
\hline
\end{tabular}

*I this study; II BPL carbon (Pigorini, 2000); III BAX carbon (Holland et al., 2001)

\section{Virial Domain}

Plots of the experimental data in the virial domain are shown in Fig. 3. Henry's Law constants were determined from these plots (extrapolation to $\mathrm{P}=0$ ) and are shown versus inverse temperature in Fig. 4 for each component. It can be seen from these plots that the Henry's Law constants increase from methane to butane, as would be expected. The slopes of the lines in
Fig. 4 are related to the heats of adsorption at low coverage. These values are shown in Table 3 compared to values obtained for BPL and BAX activated carbon. The low-coverage heat for methane is slightly less than those for the other carbons, but values for ethane and butane on the coconut carbon are significantly less than the low-coverage heats for BPL and BAX. This result could indicate differences in the pore size distribution of the three materials.

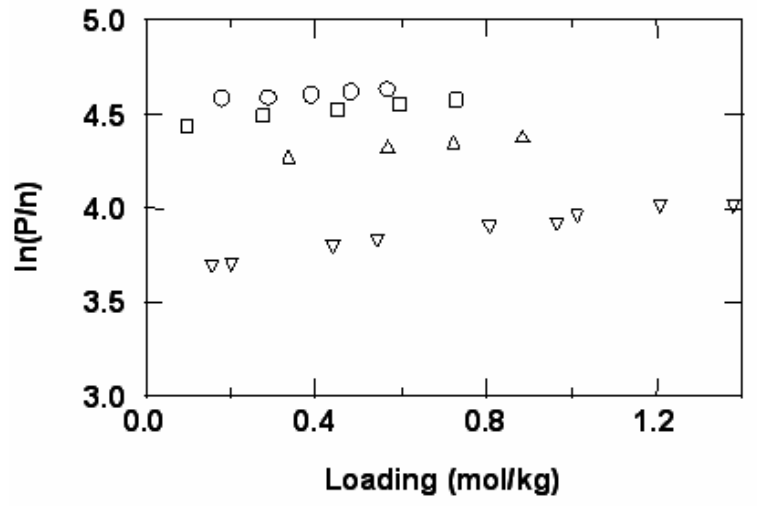

(a)

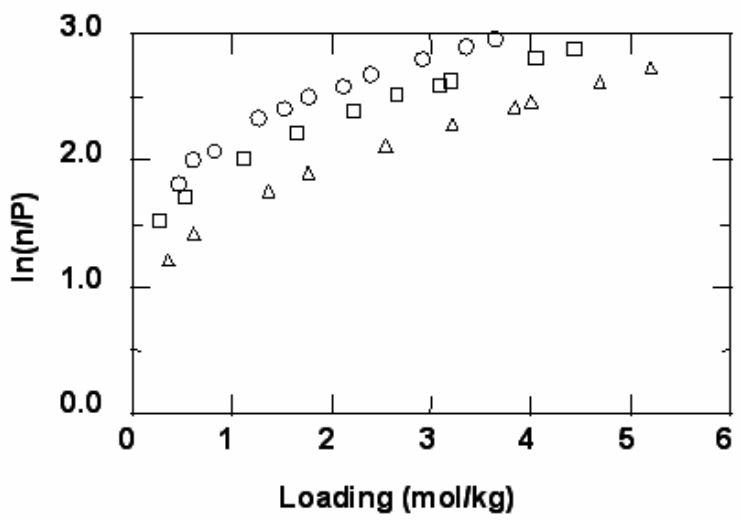

(b)

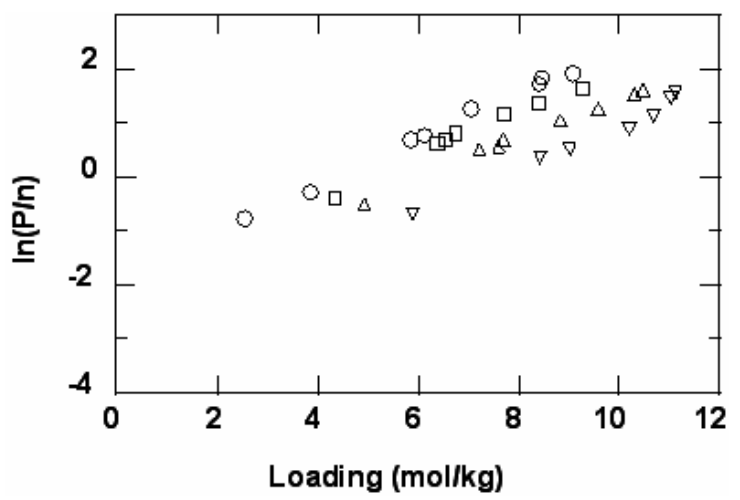

(c)

Figure 3: Viral domain plots of (a) methane (b) ethane (c) n-butane.

O $298 \mathrm{~K} ; \square 290 \mathrm{~K} ; \Delta 280 \mathrm{~K} ; \nabla 265 \mathrm{~K}$. 


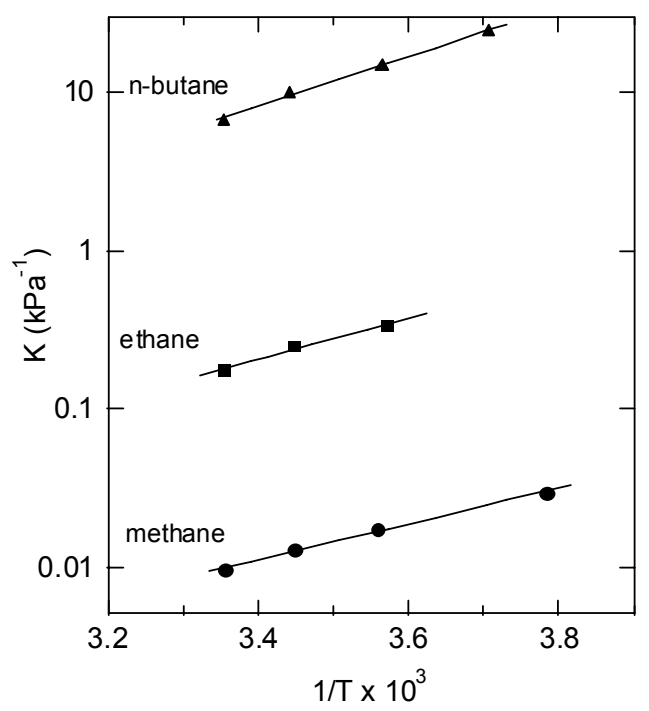

Figure 4: Henry's Law constants. Slope of each line is related to low-coverage heat of adsorption.

\section{Heats of Adsorption}

The heats of adsorption, as calculated for each component from Eq. (1), are shown in Fig. 5 as a function of loading. The heats of adsorption are assumed to be independent of temperature. By definition (Eq. (3)), the heat of adsorption calculated from the multi-temperature Toth equation (Eq. (2)) will be a constant regressed from the experimental data. These values are plotted in Fig. 5 and compare well with the heats of adsorption calculated from Eq. (1). The calculated low-coverage heats of adsorption are also plotted in Fig. 5 and appear to be reasonable values for all three components. Adsorption heats typically decrease with increasing loading, and we find this to be the case for methane and ethane (Fig. 5a,b). Butane (Fig. $5 \mathrm{c})$, however, shows a slight increase in adsorption heat with increasing loading; this could possibly indicate that lateral interactions between adsorbate molecules become important at higher loadings.

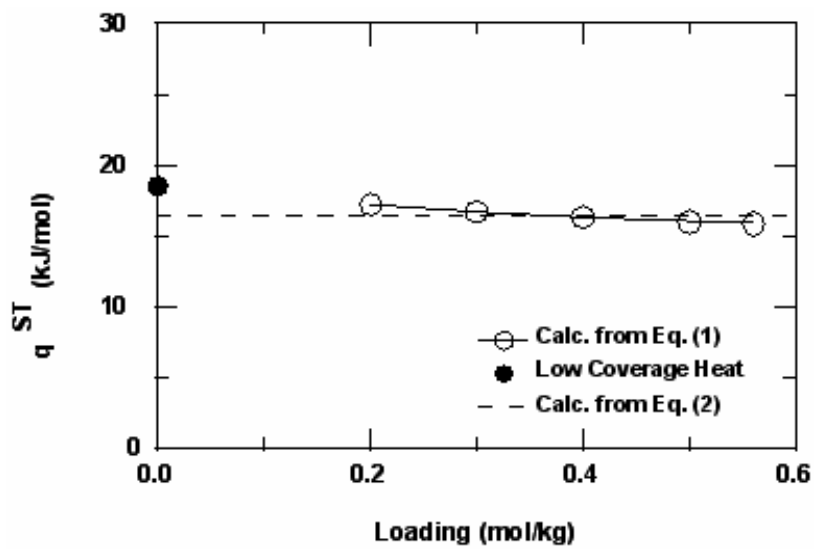

(a)

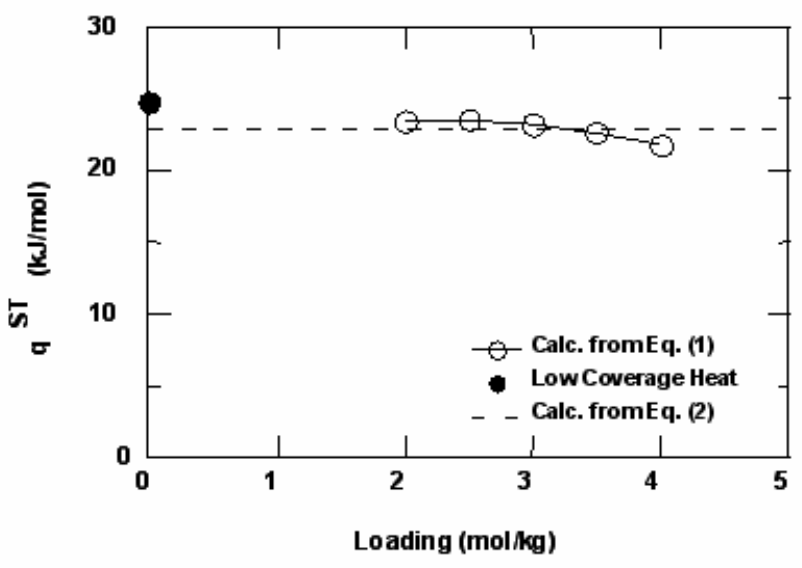

(b) 


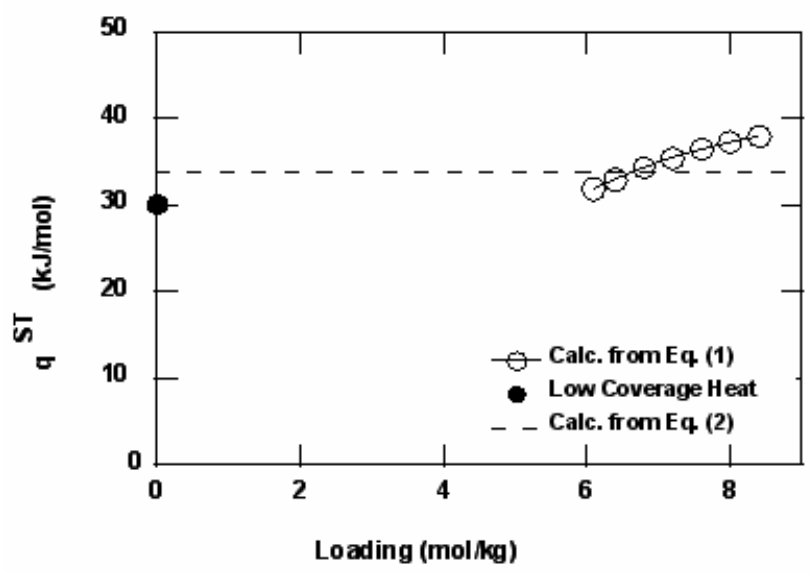

(c)

Figure 5: Calculated isosteric heats of adsorption for (a) methane (b) ethane (c) n-butane. Closed symbols are low-coverage heats calculated from slopes of lines in Fig. 4.

\section{CONCLUSIONS}

Experimental adsorption data for methane, ethane, and butane on coconut shell activated carbon have been reported for temperatures of 260-300 K and pressures up to 1 bar. Desorption measurements show reversibility of the isotherms for all three components. This material shows a marked increase in butane capacity compared to previously reported data for commercial activated carbons.

\section{REFERENCES}

Al-Muhtaseb, S. A., Holland, C. E., and Ritter, J. A., Adsorption of $\mathrm{C}_{1}-\mathrm{C}_{7}$ Normal Alkanes on BAXActivated Carbon. 2. Statistically Optimized Approach for Deriving Thermodynamic Properties from the Adsorption Isotherm, Ind. Eng. Chem. Res., 40, 319-337 (2001).

Biloe, S., Goetz, V., and Guillot, A., Optimal Design of and Activated Carbon for an Adsorbed Natural Gas Storage System, Carbon, 40, 1295-1308 (2002).

Cavalcante Jr., C. L., Torres, A. E. B., Azevedo, D. C. S., Araújo, J. C. S., and Jaguaribe, E. F., Fuel Cell Technology Topical Conference, AIChE Annual Meeting, San Francisco, CA, USA (2003).

Chang, K. J. and Talu, O., Behavior and Performance of Adsorptive Natural Gas Storage Cylinders During Discharge, Appl. Therm. Eng., 16, 359-374 (1996).
Do, H. D. and Do, D. D., Structural Heterogeneity in the Equilibrium Data for Hydrocarbons and Carbon Oxides on Activated Carbons, Gas Sep. Purif., 8, 77-93 (1994).

Holland, C. E., Al-Muhtaseb, S. A., and Ritter, J. A., Adsorption of C1-C7 Normal Alkanes on BAX Activated Carbon. 1. Potential Theory Correlation and Adsorbent Characterization, Ind. Eng. Chem. Res., 40, 338-346 (2001).

Inomata, K., Kanazawa, K., Uarabe, Y., Hosono, H., and Araki, T., Natural Gas Storage in Activated Carbon Pellets Without a Binder, Carbon, 40, 8793 (2002).

Lozano-Castello, D., Cazorla-Amoros, D., LinaresSolana, A., and Quinn, D. F., Activated Carbon Monoliths for Methane Storage: Influence of Binder, Carbon, 40, 2817-2825 (2002).

Mangun, C. L., Daley, M. A., Braatz, R. D., and Economy, J., Effect of Pore Size on Adsorption of Hydrocarbons in Phenolic-Based Activated Carbon Fibers, Carbon, 36, 123-131 (1997).

Matranga, K. R., Myers, A. L., and Glandt, E. D., Storage of Natural Gas by Adsorption on Activated Carbon, Chem. Eng.Sci, 47, 1569-1579 (1992).

Molina-Sabio, M., Almansa, C., and Rodriguez-Reinoso, F., Phosphoric Acid Activated Carbon Discs for Methane Adsorption, Carbon, 41, 2113-2119 (2003).

Mota, J. P. B., Impact of Gas Composition on Natural Gas Storage by Adsorption, AIChE J., 45, 986-996 (1999).

Mota, J. P. B., Rodrigues, A. E., Saatdjian, E., and Tondeur, D., Dynamics of Natural Gas 
Adsorption Storage Systems Employing Activated Carbon, Carbon, 35, 1259-1270 (1997).

Perrin, A., Celzard, A., Marêché, J. F., and Furdin, G., Improved Methane Storage Capacities by Sorption on Wet Active Carbons, Carbon, 42, 1249-1256 (2004).

Pigorini, G., Ph.D. dissertation, University of Virginia (2000).

Russell, B. P. and LeVan, M. D., Coadsorption of Organic Compounds and Water Vapor on BPL Activated Carbon. 3. Ethane, Propane, and
Mixing Rules, Ind. Eng. Chem. Res., 36, 23802389 (1997).

Tanaka, H., El-Merraoui, M., Steel, W. A., and Kaneko, K., Methane Adsorption on SingleWalled Carbon Nanotube: A Density Functional Theory Model, Chem. Phys. Lett., 352, 334-341 (2002).

Taqvi, S. M., Appel, W. S., and LeVan, M. D., Coadsorption of Organic Compounds and Water Vapor on BPL Activated Carbon. 4. Methanol, ethanol, Propanol, Butanol, and Modeling, Ind. Eng. Chem. Res., 38, 240-250 (1999). 